\title{
A Sensitivity Based Approach for Assessment of Reliability Indices of Electrical Distribution Systems.
}

\author{
Ganiyu Adedayo Ajenikoko ${ }^{1}$, Olusola Joel Oyedele ${ }^{2}$ \\ ${ }^{1,2}$ Department of Electronic and Electrical Engineering Ladoke Akintola University of Technology, P.M.B. \\ 4000, Ogbomoso, Nigeria.
}

\begin{abstract}
.
In Nigeria, satisfactory degree of reliability has not been attained in the power system in recent times. The average duration of interruptions that customers experience is very high and the degree varies widely especially in urban and commercial cities of the country. This research paper therefore presents the sensitivity analysis of electrical distribution systems.

Ten years of outage information from seven major distribution systems - Ibadan, Ilorin, Ikeja, Portharcourt, Kaduna, Kano and Benin were used as input data for computation of the mean and standard deviation for the system reliability indices using statistical analysis. The computed system reliability indices were used as input parameters in the analysis.

A sensitivity analysis is performed to assess how the operation parameters could influence the numerical results.

The results of the sensitivity studies indicate that Etete feeder of Benin distribution system has the highest SAIDI sensitivity of 0.5478 because of prolonged customers' interruptions on the feeder while waterworks feeder of Ilorin distribution system has the least SAIDI sensitivity of 0.0019 . Cocoa feeder of Ibadan distribution system has the highest SAIFI sensitivity of 1.0459 because of the frequent interruptions while waterworks feeder of Ilorin distribution system has the least SAIFI sensitivity of 0.0268 . Ikpoba Dam of Benin distribution system recorded the highest CAIDI sensitivity of 0.8466 with waterworks feeder also recording the least CAIDI sensitivity of 0.0075 .

The results from this research paper provides baseline information for planning and managing distribution system on Nigeria national grid.
\end{abstract}

Keywords: Sensitivity, Reliability indices, Distribution systems, SAIDI, SAIFI, CAIDI, Interruptions.

DOI: $10.7176 /$ APTA/77-07

Publication date:May $31^{\text {st }} 2019$

\section{Introduction.}

Distribution networks are normally meshed in design but the operation is nearly always configured radially. Re-configuration consists of changing the network configuration by opening/closing feeders and tie switches so that the networks become radial in operation. The configuration of distribution networks may be modified manually or by automatic switching operations for supplying the loads aiming at minimizing the cost of active power losses. Likewise, reconfiguration may increase system security and power quality (Khodr et al, 2009). Reliability indices are widely used for assessing the effectiveness of continuity of supply in distribution system. Their use is essential fro setting up performance standards for the continuity of supply regulation. Service continuity in power distribution systems is nowadays considered as an important issue, mainly because of the deregulation of the current open markets (Morales-Esparia et al, 2009).

The evolution of power systems can be traced back to many decades ago. Their primary role includes the provision of a reliable and economic supply of electrical energy to the customers. A real power system is complex, highly integrated and almost very large. It can be divided into appropriate subsystems or functional zones that can be analyzed separately. The primary role of an electric power system is to provide reliable and continuous supply of electric energy to satisfy system load.

In a broad sense, electric power system reliability can be defined as the ability of the system to provide an adequate supply of electric power with a satisfactory assurance of quality. Reliability indices are considered to be logical ways of judging the performance of an electrical power system. Power systems have three main components: generation, transmission and distribution systems. The generation system produces electricity, transmission system delivers the generated electricity to distribution systems for supplying load demands. Both the generation and transmission systems are called the composite system or the bulk power system (Meliopoulos et al, 2005; Singh and Billinton, 2005).

Assessment of customer power supply reliability is an important part of distribution system operation and planning. Distributed generation (DG) is defined by the Electric Power Research Institute (EPRI) as a small scale $(0.50 \mathrm{MW})$ energy resource connected directly to the distribution network. 
Distributed generation has a major advantage. The advantage is that, as the population expands and power generation needs change, the transmission network does not require expensive upgrades and extensions, as the generation source can be efficiently taken to the load in a more efficient manner (Stewart et al 2010).

Distribution networks are normally meshed in design but the operation is nearly always configured radially. Reconfiguration consists of changing the network configuration by opening/closing feeders and tie switches so that the networks become radial in operation.

The modification of the configuration of distribution networks may be manual or by automatic switching operations for supplying the loads aiming at minimizing the cost of active power losses. Likewise, reconfiguration may increase system security and power quality (Khodr et al, 2009).

Policies on maintenance play an important role in the reliability of repairable systems because maintenance actions can significantly affect the failure probability of the system. For a complex system, i.e. a unit with a large number of parts, the repair or the substitution of a failed part restores the system performance, but does not generally produce a significant reliability improvement because the conditions of the non-failed parts are left unchanged. In such a case, it is generally assumed that each repair brings the system to condition it was just before failure occurrence (Maurizio and Gianpaolo, 2009).

The commonly operating systems for reliability evaluation purposes are generally classified into two categories - repairable and non-repairable. For repairable systems, if a component of the system fails, it is repaired and the system is put back into operation. However, a non-repairable system dies when it fails and it needs to be replaced by a new one. The electric power systems failure falls in the category of repairable systems. Effective reliability analysis is an essential factor in long term and operational planning of electric power system (Meliopoulos et al, 2005).

Outages caused by different environmental factors on overhead lines, has a significant effect on the reliability of power distribution systems. Since animals cause significant number of outages on overhead distribution systems, it is important to investigate these outages (Khodr et al, 2009).

\section{Review of Previous Studies}

Oliveira et al (2008) presented an approach for evaluating the effects of uncertainties associated with the equipment failure parameters on composite reliability indices at bus level. The effect of failure parameter uncertainty was obtained through the exact sensitivities of composite reliability indices with variations in equipment failure and repair rates. It was shown that the sensitivities of indices at bus level also allowed the identification of the set of buses which were most affected by each of the equipment parameters defining the equipment area of influence.

A Linear Contribution Factor Model of distribution reliability indices and its application in Monte Carlo simulation and sensitivity analysis was reported by Fangxing et al (2003). This linear model could be applied to risk analysis and sensitivity analysis.

Nagaraj et al (2004) presented a computationally efficient Monte Carlo simulation technique for practical distribution system. From the analysis of outage data from a distribution system, it was found that the failures follow a renewal process. Sensitivity studies indicated that the SAIFI index was largely independent of the statistical model of the failure process while the SAIDI index depended to a greater extent on the repair duration model.

The methodology adopted by El-Kady et al (2007) was based on a combined contingency analysis/reliability evaluation influence. A three component system model which could be used effectively for evaluation and sensitivity analysis of reliability and quality in power systems was utilized. The computational technique integrated both the contingency effect and its probability of occurrence with one routine of analysis while reducing the power system around the region of interest.

Billinton (2014) illustrated a probabilistic technique to assess the operating reserve requirements in a system. In this approach, the generation system was classified into different system operating states. This technique combinds deterministic criteria with probabilistic indices to monitor the system well-being,. A risk index designated as the Generating System Operating State Risk (GSOSR) was defined as the probability of residing in an undesirable operating state. The technique together with the effect on the GSOSR and the system operating state probabilities of factors such as lead time, systems peak load, load forecast uncertainty and generating unit derated states were illustrated. The approach provided a basic framework which could be extended to include other operating capacity reserve considerations.

Allen and Bruce (2003) proposed a linear combination model for the assessment of reliability indices of a typical power network. The result of the work showed a polynomial model whose order depends majorly on the level of the networks..

Billinton and Sankarakrishnan (2014) illustrated that Monte-Carlo simulation techniques could be applied to the reliability of direct current (DC) links of composite systems. The most useful indices for quantifying the reliability of a DC link are the probability, durations and frequency of occurrence of a state or performance level. 
These indices could be estimated within a reasonable number of samples using the state transition sampling technique. The work also extended the area of adequacy assessment in composite generation and transmission systems by illustrating a method for incorporating a DC link into the analysis of an alternate current (AC) power system.

Enrico and Gianfranco (2004) presented an approach for computing the probability distributions of reliability indices of large distribution systems under the usual hypotheses concerning the fault occurrence and considering the restoration times as random variables with any type of probability distribution. The proposed approach was based on the characteristic functions, which were directly connected to central moments and exploited the properties of the compound Poisson process to avoid performing the convolutions of the Probability Distribution Functions (PDFs).

Oluseyi et al (2016) developed a novel improvement of electric power reliability scheme in Nigeria using a Demand Side Management (DSM) approach. The work discussed some of the results attained through DSM technologies in some countries as well as to raise the consciousness of Nigeria to the benefits of the DSM programs, as the nation embarks on deregulation of the power sector.

Danny (2018) examined the structure of the general transition rate matrix from which the model transition rate matrices were obtained. An exact solution to the system's state equations which depended on the Eigen-values of the model transition rate matrix, was derived. This approach was highly accurate with a controllable error, and its use was particularly effective for large systems.

Chowdhurry et al (2013) worked on reliability modeling of distributed generation in conventional distribution systems planning and analysis. The paper presented a reliability model for determining the distritributed generation equivalence to a distribution facility for use in distribution system planning studies in the new competitive environment.

Arild and Arne (2016) proposed a methodology for assessing the reliability of natural gas distribution systems based on experiences drawn from similar analysis of electrical power distribution systems. A sample test case was presented for illustrative purposes and the basic load-point reliability indices of average interruption rate, average outage time and average annual outage time were found.

Cyman (2012) worked on a computationally efficient Monte Carlo simulation technique for a practical distribution system. From the analysis of outage data from the selected distribution system, it was found that the failures followed a renewal process.

\section{Materials and Method.}

Collection of data was from the National Control Center (NCC), Osogbo. Outage information from selected distribution systems on the Nigeria National Grid were also collected from NCC Osogbo.

The following data were collected from NCC, Osogbo:

I(i) Recorded faults on the selected distribution feeders from the study period.

(ii) Recorded outage times on the selected distribution system.

(iii) Recorded number of customers' served on the distribution system.

(iv) Recorded number of customers' interruption on the distribution systems.

Statistical analysis was used in this work to compute the mean and standard deviations of the system reliability indices:- SAIDI, SAIFI and CAIDI.

Important variables considered to have sufficient inherent and relevant information were taken as random variables and characterized by their mean values and standard deviations.

In concept, every variable in an analysis can be modeled as a random variable as most properties and parameters have some inherent variability and uncertainty.

The following steps were taken in analyzing the method used.

The system reliability indices for the distribution system under study were identified

The failure rate $\lambda$ for the selected feeders on the distribution systems were computed using the relation

$$
\lambda=\frac{N}{t-t^{\prime}}
$$

Where:

$\mathrm{N}=$ the number of faults,

$\mathrm{t}$ and $\mathrm{t}$ ' represent total time and down time respectively.

iii The system reliability indices - SAIDI, SAIFI and CAIDI were computed.

(a) System Average Interruption Duration Index, SAIDI is given by 


$$
\begin{gathered}
\text { SAIDI }=\frac{\text { Customer int erruption durations }}{\text { Total Number of Customers Served }} \\
=\frac{\sum_{i=1}^{n} r_{i} N_{i}}{\sum_{i=1}^{n} N_{T}}
\end{gathered}
$$

(b) System Average Interruption Frequency Index, SAIFI is given by

$$
\begin{aligned}
& \text { SAIFI }=\frac{\text { Total number of customer int erruptions }}{\text { Total Number of Customers Served }} \\
& \frac{\sum_{i=1}^{n} N_{i}}{\sum_{i=1}^{n} N_{T}}
\end{aligned}
$$

(c) Customer Average Interruption Duration Index, CAIDI is given by

$$
\begin{gathered}
\text { CAIDI }=\frac{\text { Customer int erruption durations }}{\text { Total Number of Customers Interruption }} . \\
=\frac{\sum_{i=1}^{n} r_{i} N_{i}}{\sum_{i=1}^{n} N_{i}}
\end{gathered}
$$

where:
ri $\quad=$
Restoration time for each interruption for the ith customer.
$\mathrm{Ni}=\quad$ Number of interrupted customers for each interruption event during reporting period.
NT $=\quad$ Total number of customers served for area being indexed.

iv. The mean values and standard deviations of the system reliability indices were computed.

The mean value $\mu \mathrm{x}$ of a set of $\mathrm{N}$ measured values for the random variables $\mathrm{X}$ is obtained by summing the values and dividing by $\mathrm{N}$.

$$
\mu_{X}=\frac{\sum_{i-1}^{N} X_{i}}{N}
$$

Expected value:

The expected value $\mathrm{E}[\mathrm{X}]$ of the random variable is the mean value obtained if all possible values of the random variables were multiplied by their likelihood of occurrence and summed. The mean and expected value are numerically the same.

Where:

$$
\begin{aligned}
E[X] & =\mu_{x} \\
& =\int X f(x) d x \\
& =\sum X_{P}\left(X_{i}\right)
\end{aligned}
$$

$\mathrm{f}(\mathrm{x})=$ probability density function of $X$

$\mathrm{P}(\mathrm{Xi})=$ probability density function of $\mathrm{Xi}$

\section{Variance:}

The variance $\operatorname{Var}[\mathrm{X}]$ of a random variable $\mathrm{X}$ is the expected value of the squared difference between the random and its mean value. 


$$
\begin{aligned}
\operatorname{Var} & {[X]=E\left[\left(X-\mu_{x}\right)^{2}\right] } \\
& =\int\left(X-\mu_{x}\right)^{2} f(x) d x \\
& =\frac{\sum\left[\left(X_{i}-\mu_{x}\right)^{2}\right]}{N}
\end{aligned}
$$

Standard deviation:

To express the scatter or dispersion of a random variable about its expected value in the same unit as the random variable itself, the standard deviation $\sigma \mathrm{x}$ was taken as the square root of the variance. Thus:

$$
\sigma_{x}=\sqrt{\operatorname{Var}[X]}
$$

The contributions to each of the system reliability indices from the feeders were computed. Sensitivity analyses were performed for the system reliability indices. Sensitivity ' $\mathrm{S}$ ' is given by

$$
S=\frac{r^{\prime}-r}{M T B F}=\lambda\left(r^{\prime}-r\right)
$$

where:

$\begin{array}{cll}\mathrm{S} & = & \\ \mathrm{r} & = & \text { sensitivity of the reliability index } \\ \mathrm{r} 1 & = & \text { reliability index with the conventional LCF model } \\ \lambda & = & \text { Failure rates of the feeders } \\ \text { MTBF } & = & \text { Mean }- \text { time }- \text { between failures of the feeders. }\end{array}$

\section{Discussion of Results.}

The sensitivities for the seven distribution systems used as case studies in this research work are as shown in Figures 1 to 7.

Observations from Figure 1.0 show that Cocoa feeder of Ibadan distribution system has the highest SAIDI sensitivity of 0.6181 because many customers were interrupted for a prolonged time while fewer customers were effectively served by this distribution feeder. The least SAIDI sensitivity of 0.1634 was recorded by Agodi feeder of Ibadan distribution system as shown in Figure 1.. Customers on this feeder were interrupted for a shorter time while many of the customers attached to this feeder were served adequately. The SAIFI sensitivity for Cocoa feeder of Ibadan distribution system is 1.0459 . This feeder has the highest SAIFI sensitivity. This is because customers on this feeder were frequently interrupted, thus leading to epileptic service to numerous customers while only few of the customers were adequately served.

Agodi feeder of Ibadan distribution system experienced a least SAIFI sensitivity of 0.1883 . Customers interruptions on this feeder were appreciably reduced, thus providing an adequate service to many customers connected to the feeder.

The highest CAIDI sensitivity of 2.2984 was recorded on Ijokodo feeder of Ibadan distribution system because some of the customers on this feeder were interrupted for a long time, thereby putting them in a long period of complete darkness.

Eruwa feeder of Ibadan distribution system has been observed to have the least CAIDI sensitivity of 0.7111 because some of the customers on this feeder were interrupted for a short period of time after which the faults were cleared.

Ganma feeder of Ilorin distribution system has the highest SAIDI sensitivity of 0.0992 because of the prolonged time of interruption by customers on this feeder. The least SAIDI sensitivity of 0.0019 was recorded by Waterworks feeder of Ilorin distribution system because of a shorter time of customer interruption on this feeder.The SAIFI sensitivity of Ganma feeder of Ilorin distribution system was 0.5690 which appears to be the highest on this feeder. Customers on this feeder were frequently interrupted thereby leading to epileptic services to numerous customers

The least SAIFI sensitivity of 0.0268 was experienced by Waterworks feeder of Ilorin distribution system because adequate services were rendered to customers connected to this feeder. The highest CAIDI sensitivity of 0.5153 was recorded on Gaoma feeder of Ilorin distribution system because some of the customers on this feeder were interrupted for a long time, thus putting them in a prolonged period of complete darkness.

Waterworks feeder of Ilorin distribution system has the least CAIDI sensitivity of 0.0075 . Some of the customers on this feeder were interrupted for a short period of time after which the faults were cleared asillustrated 
in Figure 2. Opebi feeder of Ikeja distribution system has the highest SAIDI sensitivity of 0.1554 and a least SAIDI sensitivity of 0.0716 was recorded by General hospital feeder of Ikeja distribution system. The SAIFI sensitivity for Alagbole feeder of Ikeja distribution system is 0.5278 which is the highest in this case while Olowu feeder has the least SAIFI sensitivity of 0.1977 since customer interruptions on this feeder were appreciably reduced.

The highest CAIDI sensitivity of 0.8328 was recorded on Opebi feeder of Ikeja distribution system as shown in Figure 3. while the least CAIDI sensitivity of 0.3076 was recorded on General Hospital feeder of Ikeja distribution system since customers on this feeder were interrupted for a shorter period of time after which the faults were cleared.

Figure 4 shows that Portharcourt town 1 feeder of the Portharcourt distribution system has the highest SAIDI sensitivity of 0.1314 and a least SAIDI sensitivity of 0.0456 was recorded by Shell 2 feeder of Portharcourt distribution system. The highest SAIFI sensitivity of 0.1881 was recorded by Shell 3 feeder of PortHarcourt distribution system and a least SAIFI sensitivity of 0.1141 was recorded by Shell 2 feeder of PortHarcourt distribution system because adequate services were provided to many customers connected to this feeder.

The highest CAIDI sensitivity of 0.9317 was recorded on Airport feeder of Port-Harcourt distribution system while a least CAIDI sensitivity of 0.2708 was recorded on Shell 2 feeder of Port-Harcourt distribution system because some of the customers on this feeder were interrupted for a short time period after which the faults were cleared.

Observations from Figure 5 show that FDR2 feeder of Kaduna distribution system has the highest SAIDI sensitivity of 0.1946 while the least SAIDI sensitivity of 0.0889 was recorded by Junction Road feeder of Kaduna distribution system because customers on this feeder were interrupted for a shorter time while many of the customers attached to this feeder were adequately served. The highest SAIFI sensitivity of 0.5212 was recorded on St. Gorald feeder of Kaduna distribution system while the least SAIFI sensitivity of 0.1739 was recorded on FDR3 feeder of Kaduna distribution system.

Figure 6 shows that the highest CAIDI sensitivity of 0.8137 was recorded on FDR2 feeder of Kaduna distribution system while the least CAIDI sensitivity of 0.3611 was recorded on Junction road feeder of Kaduna distribution system. Some of the customers on this feeder were interrupted for a short period of time after which the faults were cleared. Banguda feeder of Kano distribution system has the highest SAIDI sensitivity of 0.3017 while Spare feeder of Kano distribution system has the least SAIDI sensitivity of 0.0477 as shown in Figure 6.0. The highest SAIFI sensitivity of 0.4912 was recorded on Banguda feeder of Kano distribution system while the least SAIFI sensitivity of 0.1983 was recorded on Waterworks feeder of Kano distribution system.

The highest CAIDI sensitivity of 1.2922 was recorded on Bangauda feeder of Kano distribution system with the least CAIDI sensitivity of 0.2001 recorded also on Bangauda feeder of Kano distribution system because customers on this feeder were interrupted for a short period of time after which the faults were cleared.

Figure 7 shows that Etete feeder of Benin distribution system has the highest SAIDI sensitivity of 0.5478 and GRA feeder of Benin distribution system has the least SAIDI sensitivity of 0.1086 because customers on this feeder were interrupted for a shorter time. The highest SAIFI sensitivity of 0.7770 was recorded on Etete feeder of Benin distribution system while the least SAIFI sensitivity of 0.2209 was recorded on GRA feeder of Benin distribution system. For this feeder, customers' interruptions were appreciably reduced, thus providing an adequate service to many customers connected to it.

The highest CAIDI sensitivity for Benin distribution system was recorded on Ikpoba Dam with a value of 2.8466 while the least CAIDI sensitivity of 0.5123 was recorded on GRA feeder of Benin distribution system. Some of the customers on this feeder were interrupted for a short time period after which the faults were cleared. 


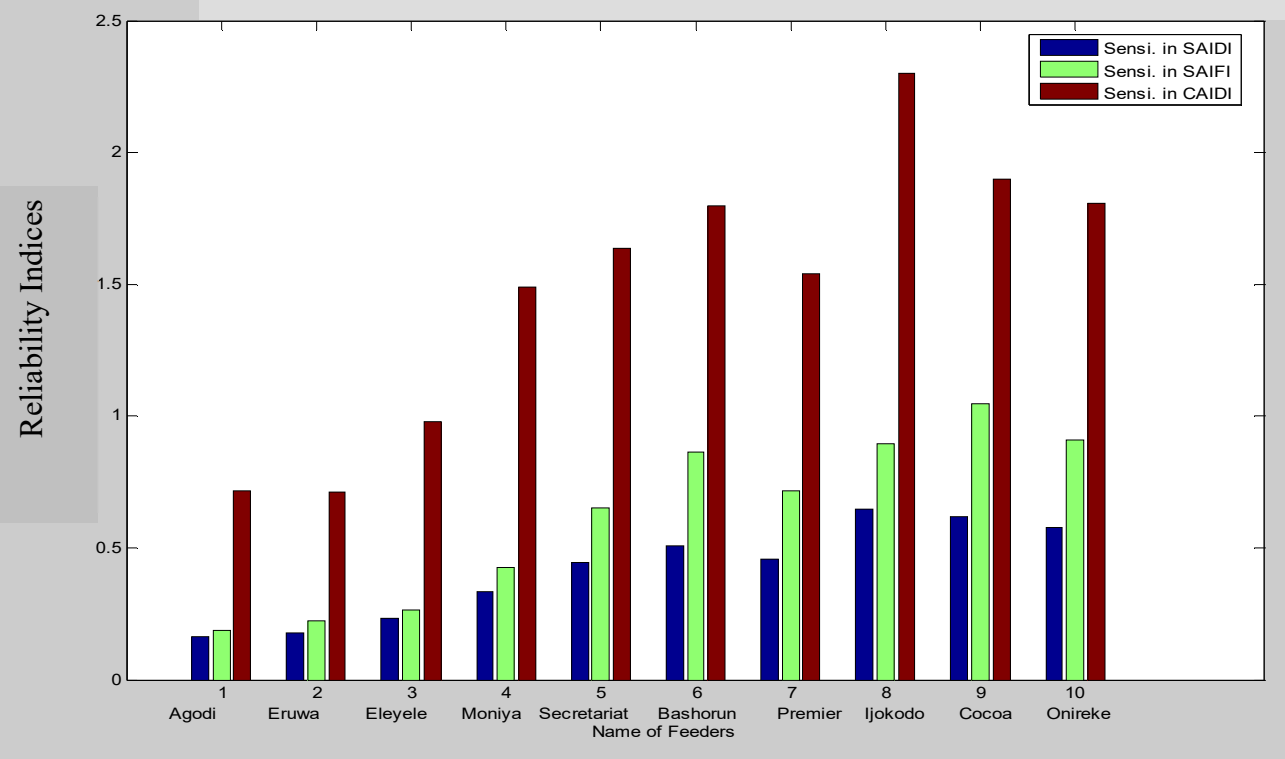

Figure 1: Sensitivity analysis of Reliability Indices for Ibadann Distribution Systems

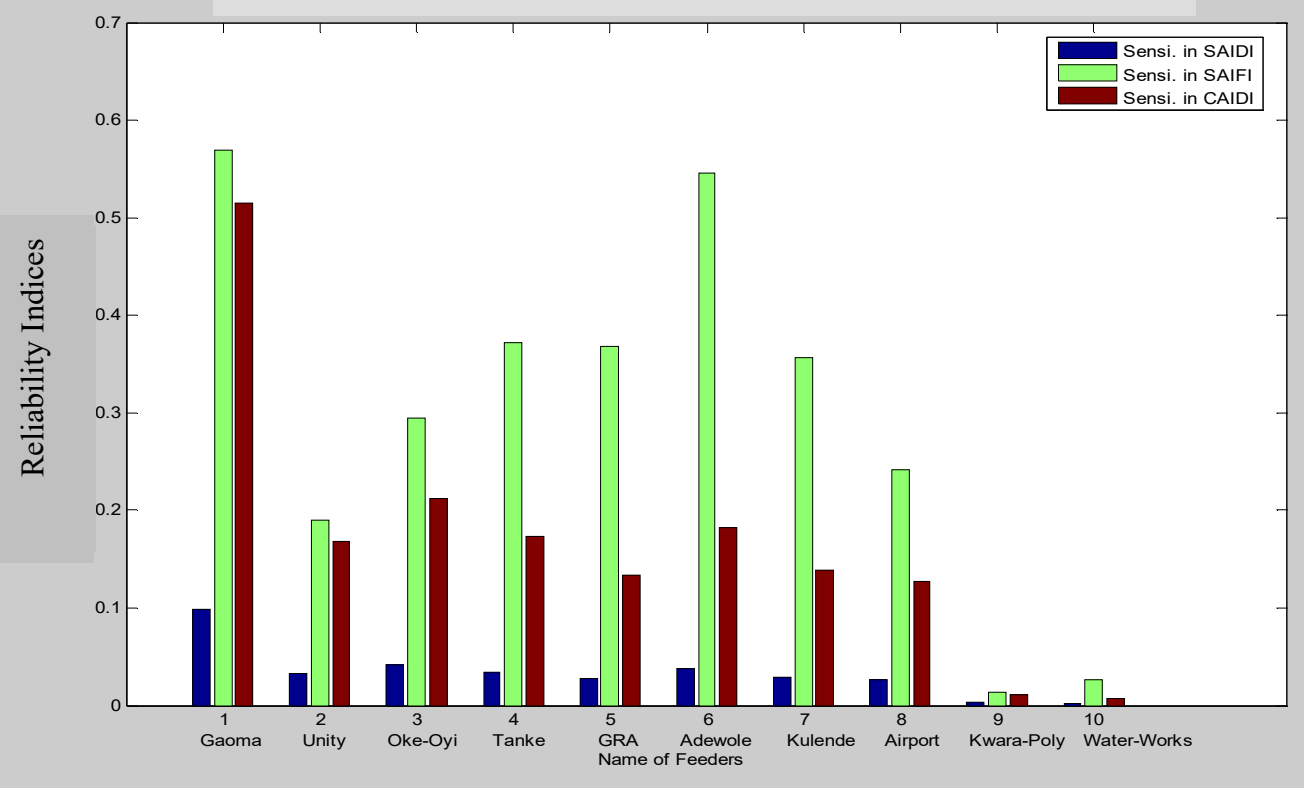

Figure.2: Sensitivity analysis of Reliability Indices for Ilorin Distribution Systems 


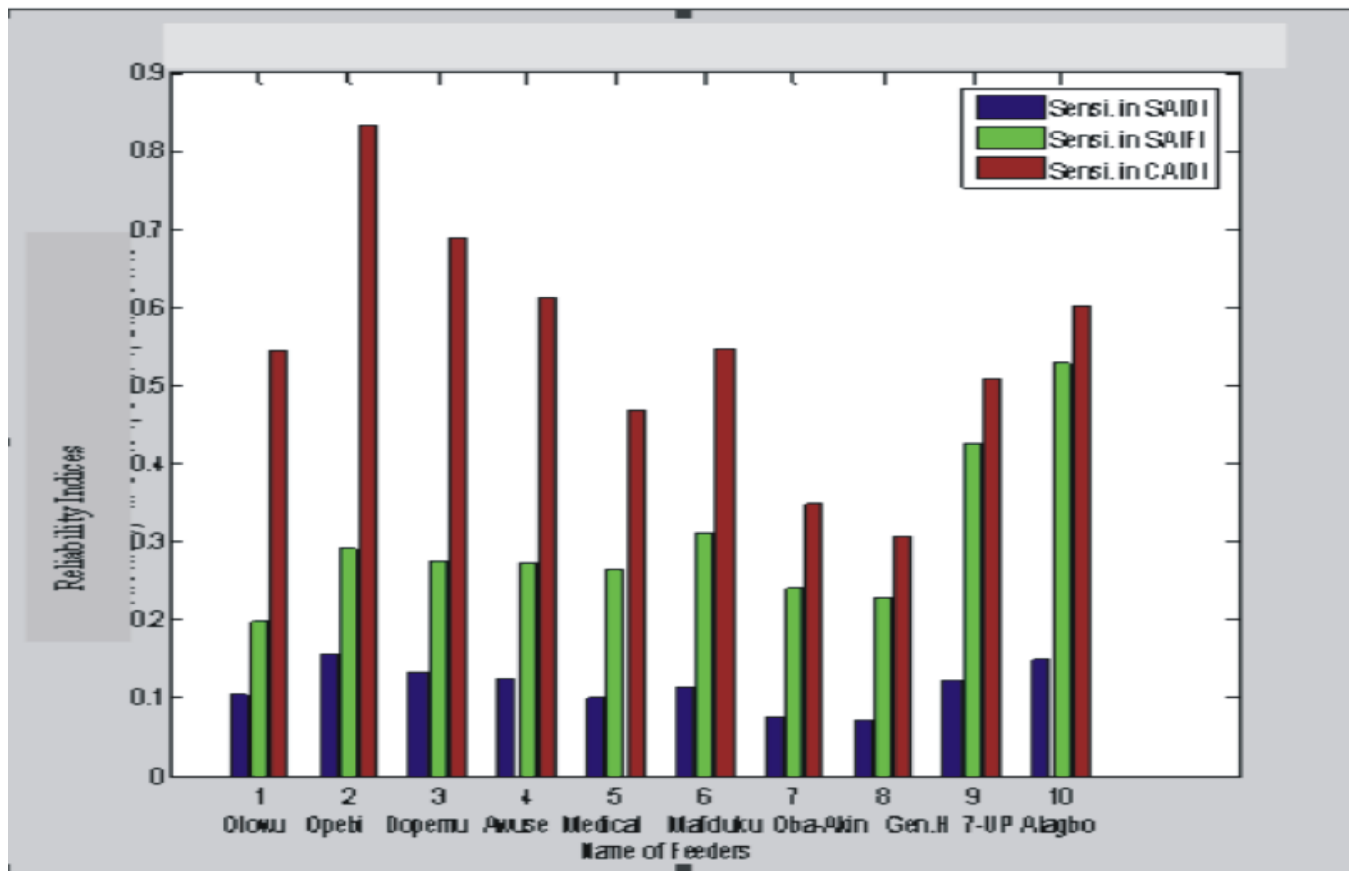

Figure 3: Sensitivity analysis of Reliability Indices for Ikeja Distribution Systems

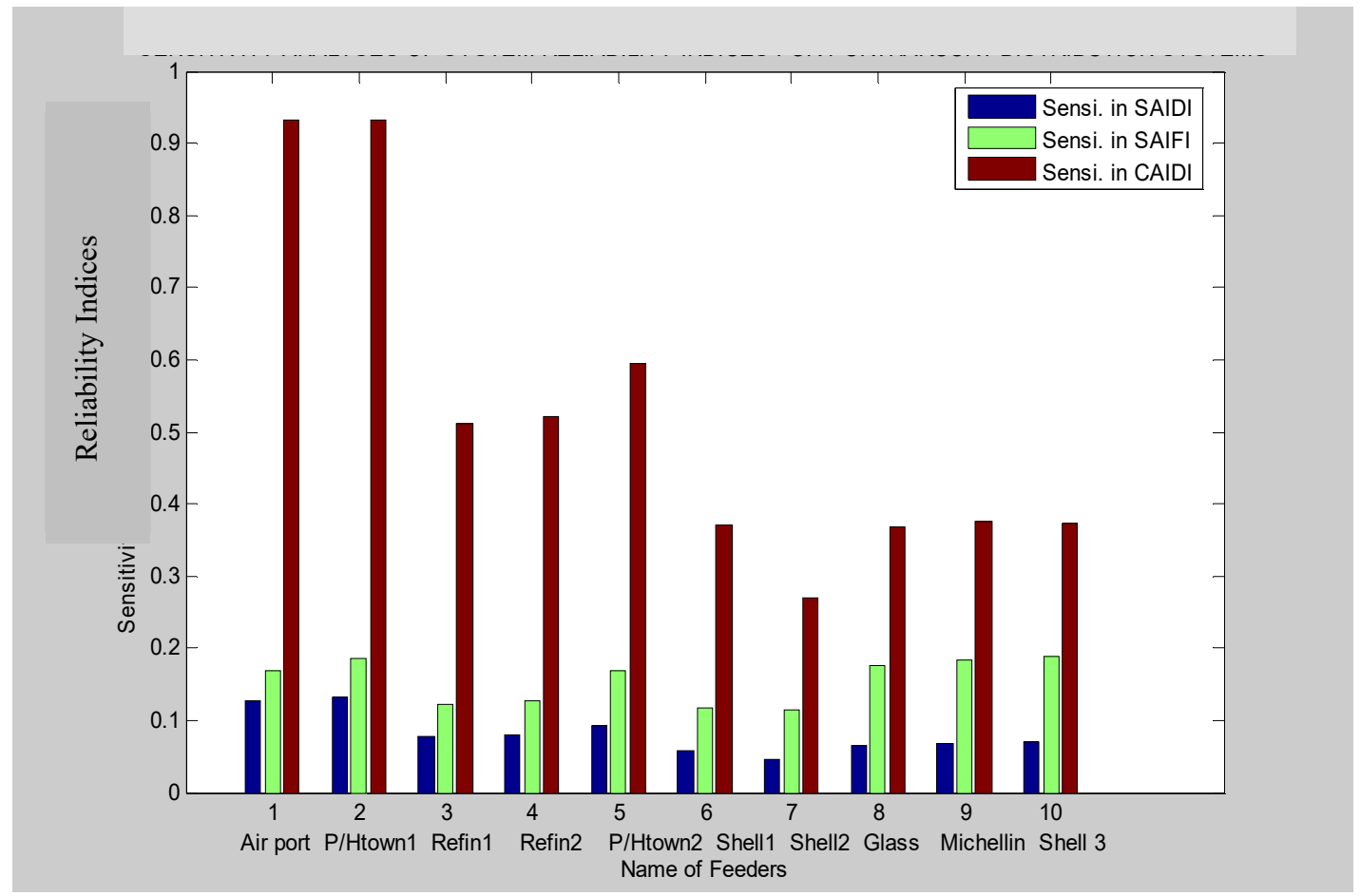

Figure 4: Sensitivity analysis of Reliability Indices for Portharcourt Distribution Systems 


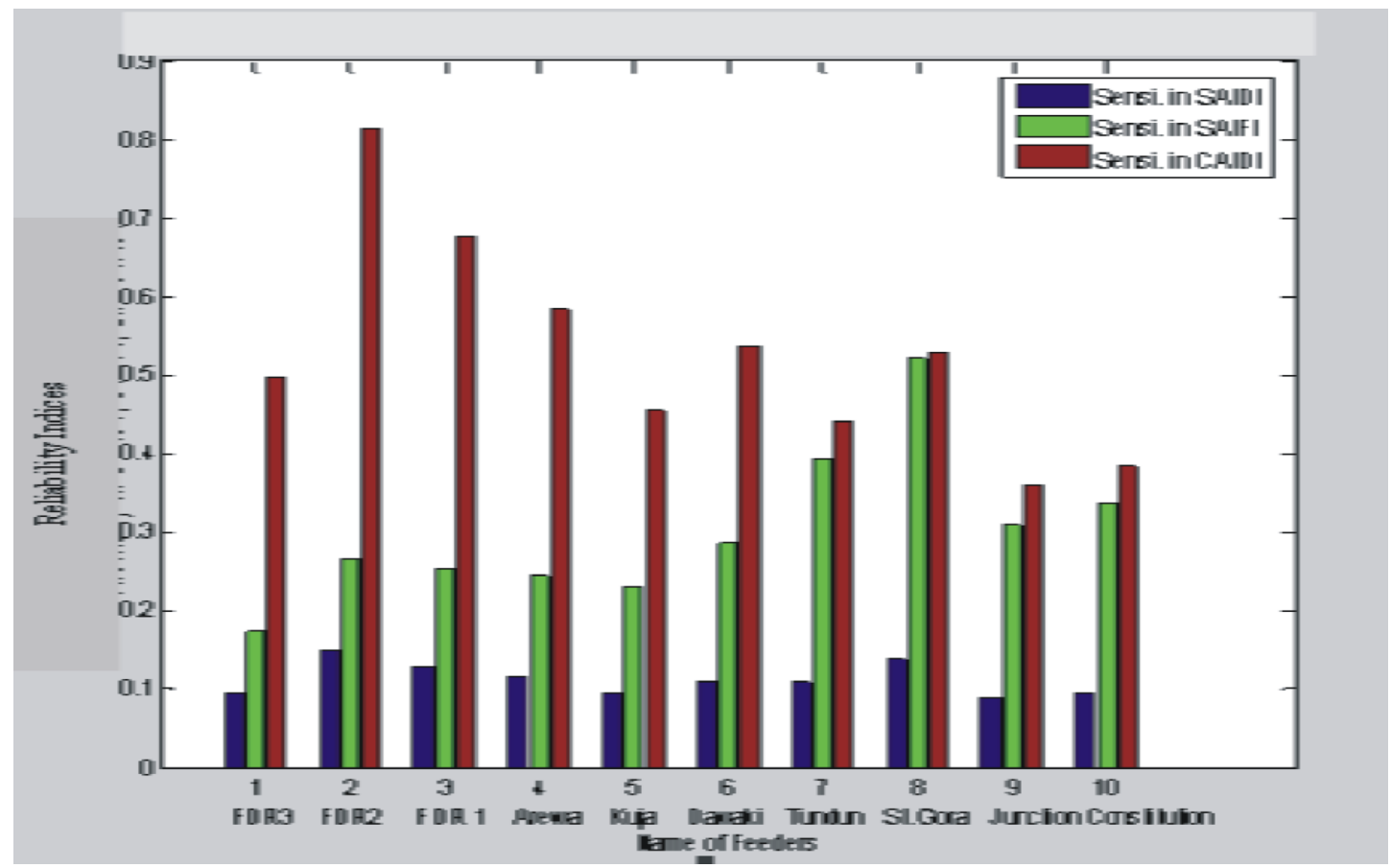

Figure 4.5: Sensitivity analysis of Reliability Indices for Kaduna Distribution Systems

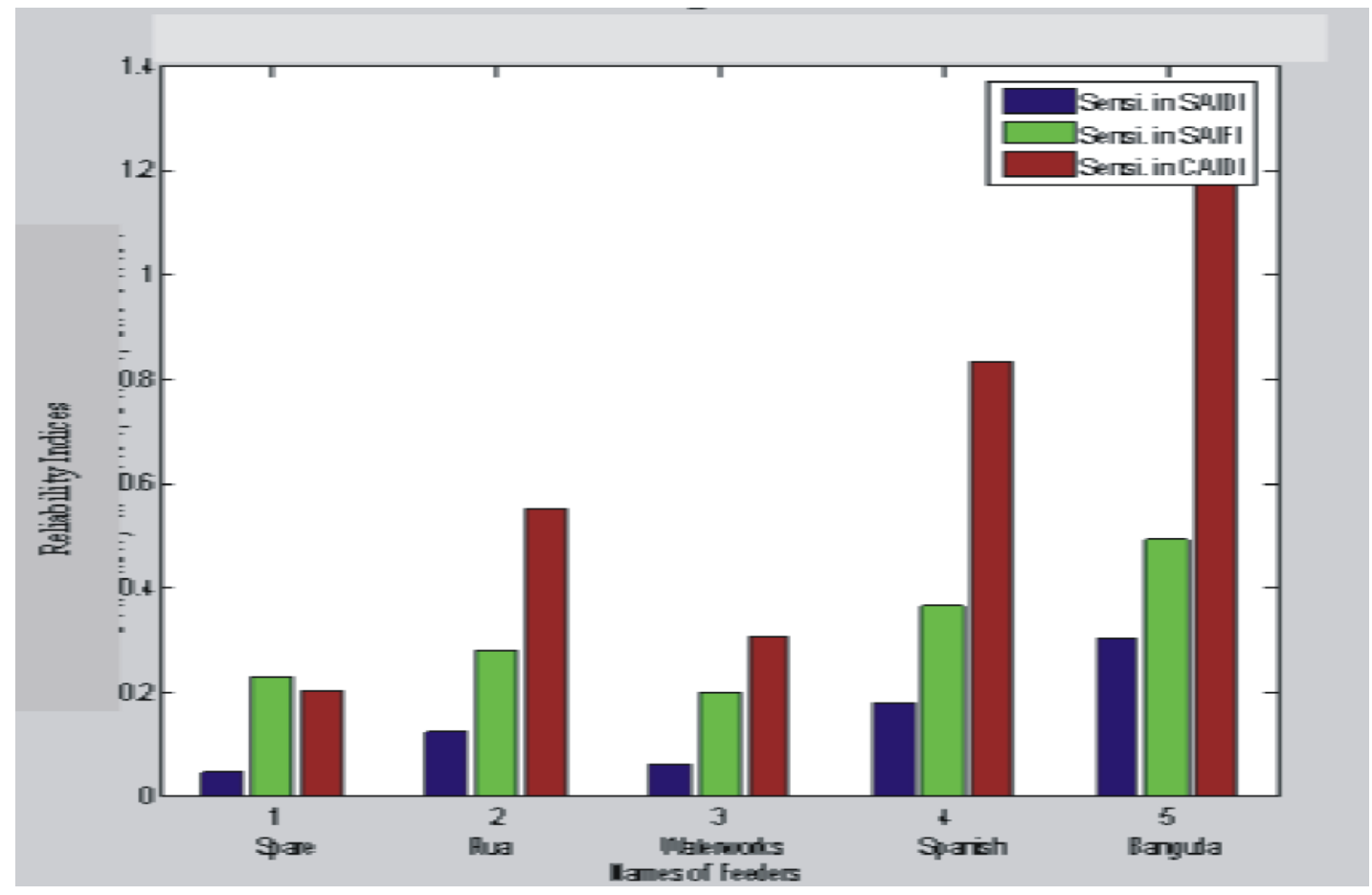

Figure 4.6: Sensitivity analysis of Reliability Indices for Kano Distribution Systems 


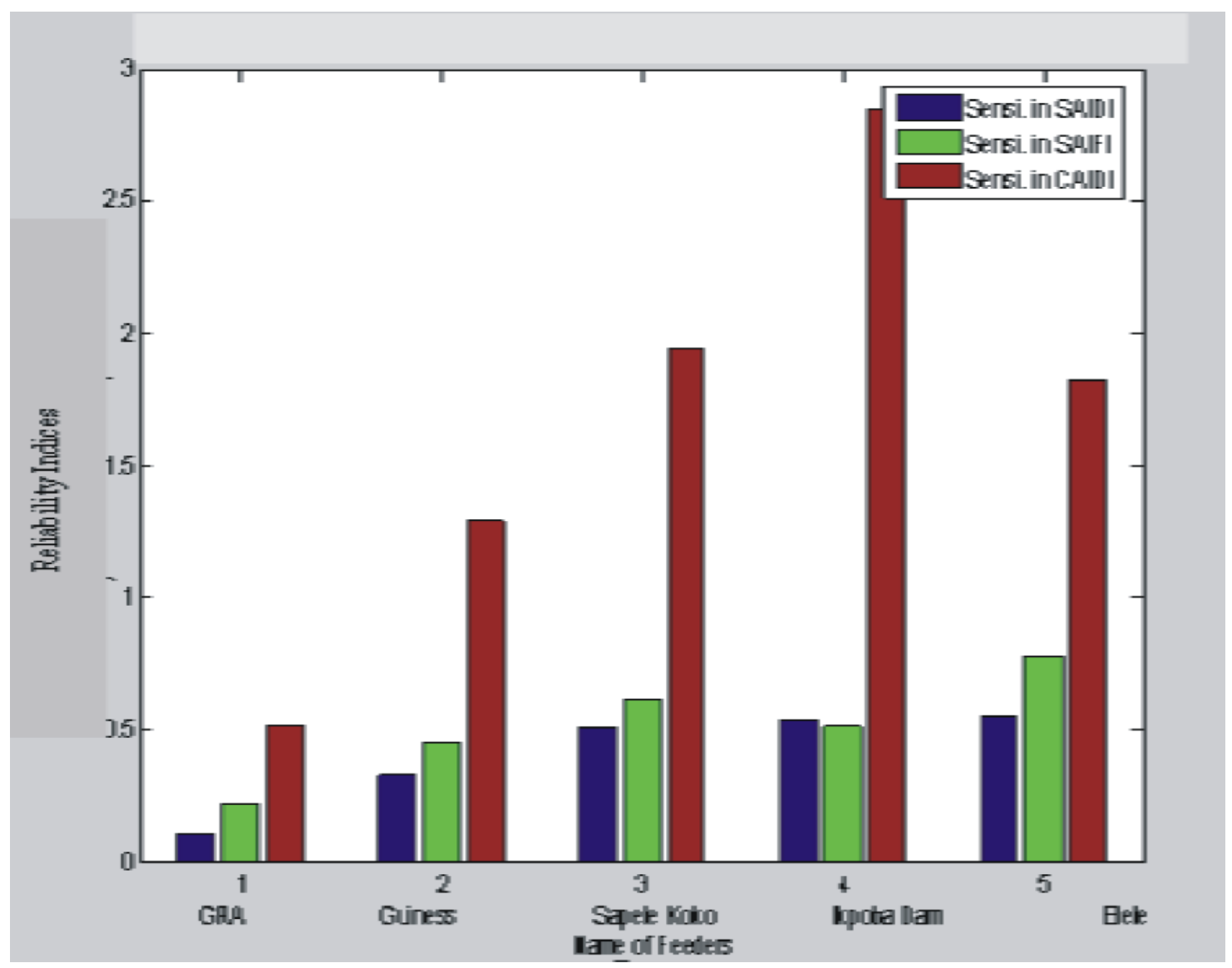

Figure 4.7: Sensitivity analysis of Reliability Indices for Benin Distribution Systems

\section{Conclusion.}

Etete feeder of Benin distribution system recorded the highest SAIDI sensitivity of 0.5478 as a result of prolonged customers' interruptions on this feeder compared to all other feeders in the distribution systems. Waterworks feeder of Ilorin distribution system has the least SAIDI sensitivity because customers' interruptions on this feeder are less prolonged. Cocoa feeder of Ibadan distribution system recorded the highest SAIFI sensitivity of 1.0459 while waterworks feeder of Ilorin distribution had the least SAIFI sensitivity of 0.0268. Ikpoba dam of Benin distribution system had the highest CAIDI sensitivity of 2.8466 with waterworks feeder of Ilorin distribution system having the least CAIDI sensitivity of 0.0075 .

\section{References}

Arild and Ame (2016):" Reliability Indices Computations", International Journal of Engineering Research Applications, Volume 2, Number 5, Pp 65-76.

Billinton (2014):" Impact of reliability indices on Distribution networks", Journal of Advanced Sciences and Power System" Volume.2, Number 7, Pp 23-31.

Billinton T.Y and Sankarakrishnan W.T (2014):"Reliability evaluation of Network reconfiguration", Journal of Computer Engineering, Volume.6, Number 3, Pp 43-51.

Chowdhurry T.V, Rita W and Paul E (2013) :" A Simplified Method of Evaluating Reliability Indices of Distribution Systems", International Journal of Electrical Engineering, Volume .12, Number 8, Pp 43-53. 
Danny (2018): “ Estimation of Distribution Sytems Reliability Indices using Analytical Approach”, International Journal of Innovative Research Studies, Volume 2, Number 6, Pp 56-61.

El-Kady M. A, Alaskar B. A, Shaalan A. M, and Shammri B.M (2007): "Composite reliability and quality assessment of interconnected power systems”. IEEE Transactions on Power Systems, Volume. 11, No. 5, pp 328396.

Enrico R.U. and Gianfranco T.E.(2014): "Reliability assessment of Distribution networks”, International Journal of Electrical Engineering, Vol.2, Number 8, Pp 31-36

Fangxing Li, Richard E. B. and Lavelle A. A. F. (2003):” A linear contribution factor model of distribution reliability indices and its applications in Monte Carlo simulation and sensitivity analysis" IEEE Transaction on power systems, Volume 18, No 3, pp 93-98.

Khodr H.M, Martinez-Crespo J, Matos M. A and Pereira J. (2009): "Distribution Systems reconfiguration based on OPF using Benders decomposition”, IEEE Transactions on power delivery, Volume. 24, No. 4, pp. $2166-2176$.

Maurizio R and Gianpaolo (2009):"Reliability indices Computational methods,”, Journal of Electrical Engineering, Volume.10, Number 2, Pp 73-81.

Meliopoulos D.Y,Amos R.O and Yellow N (2005): "Reliability evaluation of Distribution networks", Journal of Electrical Engineering, Volume.2, Number 6, Pp 23-31.

Morales-Esparia G, Mora-Florez J and Vargas-Torres H (2009): "Elimination of multiple estimation for fault location in radial power systems by using fundamental single-end measurements", IEEE transactions on power system, Volume. 24, No. 3, Pp 1382-1389.

Nagaraj B., Subrahmanyam S. V. and Richard D C. (2004): "Modelling and analysis of distribution reliability indices." IEEE Transactions on power delivery, Volume. 19, No. 4, pp. 101-109.

Oliveira A. M., Melo A.C.G and Pinto L.M.V.G (2008): "Consideration of equipment failure parameter uncertainties in bus composite reliabilities indices". IEEE Transactions on Power Apparatus and Systems, Volume. 6, No. 4, pp 448-453

Oluseyi T, Tweew R.T, Douglas E.W (2016) :" Analysis of Reliability indices of power Distribution networks", International Journal of Electrical and Computer Engineering", Volume.12, Number 3, Pp 51-70.

Singh Y and Billinton E (2005) : “Analysis of reliability indices for distribution systems"،”, Journal of Electrical Power Systems . Volume.8, Number 4, Pp 43-51..

Stewart T, Mamood R and Bruce W (2010): “"Reliability indices in the perspective of Customers”, Journal of Power Systems Engineering,Volume.6, Number 3 Pp 19-21. 